\title{
Energetics of the primary electron transfer reaction revealed by ultrafast spectroscopy on modified bacterial reaction centers
}

\author{
S. Schmidt a , T. Arlt ${ }^{a}$, P. Hamm ${ }^{\text {a }}$, H. Huber ${ }^{\text {a }}$, T. Nägele ${ }^{a}$, J. Wachtveitl ${ }^{\text {a }}$, M. Meyer ${ }^{\text {b }}$, \\ H. Scheer ${ }^{b}$, W. Zinth ${ }^{\text {a }}$ \\ - Institut für Medizinische Optik, Ludwig-Maximilians-Universität München, Barbarastraße 16, D-80797 München, Germany \\ botanisches Institut, Ludwig-Maximilians-Universität München, Menzinger Straße 67, D-80638 München, Germany
}

Received 18 March 1994

\begin{abstract}
The modification of reaction centers from Rhodobacter sphaeroides by the introduction of pheophytins instead of bacteriopheophytins leads to interesting changes in the primary photosynthetic reaction: long-living populations of the excited electronic state of the special pair $\mathrm{P}^{*}$ and the bacteriochlorophyll anion $\mathrm{B}_{\mathbf{A}^{-}}$show up. The data allow the determination of the energetics in the reaction center. The free energy of the first intermediate $\mathrm{P}^{+} \mathrm{B}_{\mathbf{A}}^{-}$, where the electron has reached the accessory bacteriochlorophyll $\mathrm{B}_{\mathrm{A}}$ lies $\approx 450 \mathrm{~cm}^{-1}$ below the initially excited special pair $\mathrm{P}^{*}$.
\end{abstract}

\section{Introduction}

The solution of the molecular structure of photosynthetic reaction centers [1-3] provides detailed information on the organization of this pigmentprotein complex, in which a series of light-induced electron transfer steps initiates bacterial photosynthesis. The dynamics of this process has been investigated by time-resolved spectroscopy, complementing the structural data. Optical excitation leads to the transfer of an electron from a pair of strongly coupled bacteriochlorophyll molecules [4] to a quinone on the opposite side of the membrane (see inset Fig. 1). Only one of the two symmetrically arranged chains of chromophores [1-3] is used for the electron transfer. At present, the role of the first chromophore in the chain, the monomeric bacteriochlorophyll $\mathrm{B}_{\mathrm{A}}$, is still under debate [5-7]. Experimental on native reaction centers have shown that a population of the anion state $\mathbf{B}_{\mathbf{A}}^{-}$would be small, short lived and thus difficult to detect [8-11]. The ultrafast electron transfer (ET) reactions along the chromophore chain (see inset Fig. 1) in photosynthetic reaction centers (RCs) leads to a reduction of the quinone $Q_{A}$ within $\approx 200 \mathrm{ps}$ [14]. The preceding intermediate, the radical pair state $\mathrm{P}^{+} \mathrm{H}_{\mathrm{A}}^{-}$, where the electron resides on the bacteriopheophytin $\mathrm{H}_{\mathrm{A}}$, is formed within 3 ps [511]. The decay of the initially excited special pair state $P^{*}$ occurs on the same time scale $[5,8,12,13,15]$. Two basic reaction models are currently discussed for the role of the monomeric bacteriochlorophyll $\mathbf{B}_{\mathbf{A}}$ $[16,17]$. in the superexchange model, the free energy $G\left(\mathrm{P}^{+} \mathrm{B}_{\mathrm{A}^{-}}\right)$of the radical pair state $\mathrm{P}^{+} \mathrm{B}_{\mathrm{A}^{-}}$lies well above that of $P^{m}[18,19]$. As a consequence, $P^{+} B_{\bar{A}}^{-}$ is not populated and the electron is transferred directly to $\mathrm{H}_{\mathrm{A}}$. In the stepwise model, $G\left(\mathrm{P}^{+} \mathrm{B}_{\mathrm{A}}^{-}\right)$is close to that of $\mathrm{P}^{*}$ or lower and $\mathrm{P}^{+} \mathrm{B}_{\mathrm{A}}^{-}$is a real intermediate in the ET reaction $[18,19]$. Access to selectively modified reaction centers yields unprecedented possibilities for determining the role of $B_{A}$ and to decide on the reaction mechanism.

In this Letter, we present sub-picosecond experi- 


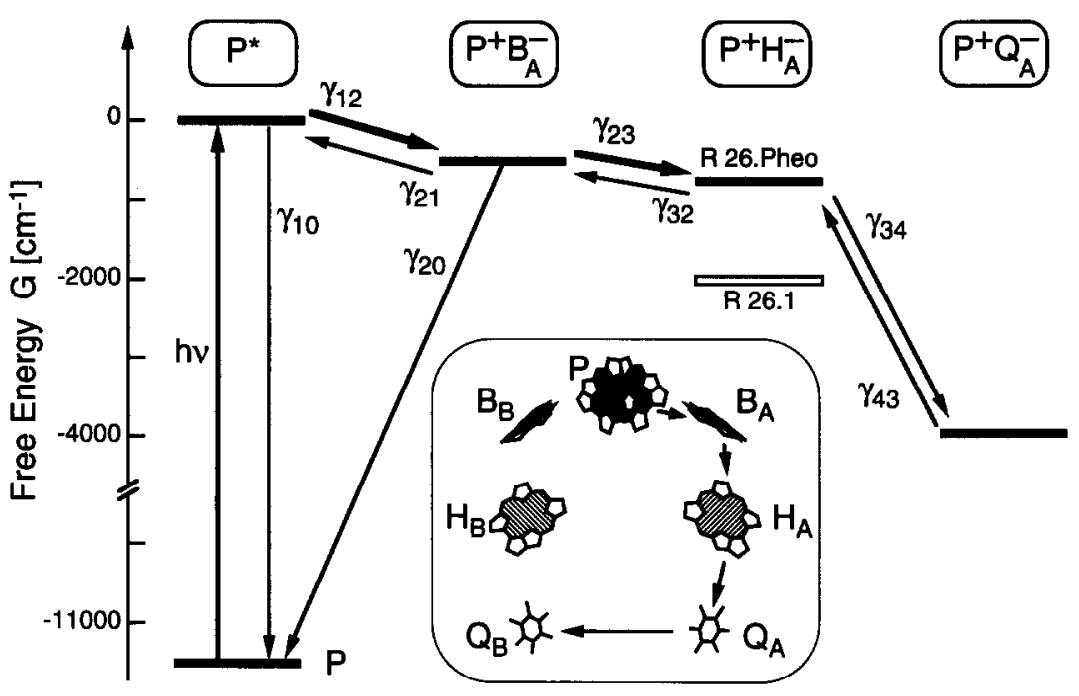

Fig. 1. Reaction scheme used to explain primary photosynthesis in bacterial reaction centers of $R b$. sphaeroides. It is based on a step-wise ET along the pigment chain of the reaction center (see inset) from the special pair $P$ via $B_{A}, H_{A}$ and $Q_{A}$. For simplicitly, the initial reaction away from the special pair $P^{*}$ is assumed to be monoexponential, even if the experiments on wild-type RCs and modified RCs R26.Phe-a have indicated some heterogeneity of this reaction step $[12,13]$. Since interpretation of this feature does not interfere with the essence of this Letter, we do not consider here the non-monoexponentiality in detail.

ments on reaction centers where the redox potential of one electron acceptor in the chain was raised. We concentrate on data from a spectral region free of ground state pigment absorption where the bacteriochlorophyll anion can be followed directly.

\section{Materials and methods}

The time-resolved experiments are performed at room temperature $(295 \mathrm{~K})$ by a sub-picosecond laseramplifier system [20]. Sub-picosecond weak $(<15 \%$ excitation) and short ( $\left.t_{\mathrm{p}} \approx 150 \mathrm{fs}\right)$ light pulses at $\lambda_{\text {exc }}=870 \mathrm{~nm}$ are used to excite the special pair. Properly delayed probing pulses at $\lambda_{\mathrm{Pr}}=1020 \mathrm{~nm}$ are obtained by continuum generation. They interrogate the absorbance changes as a function of time delay $t_{\mathrm{D}}$. Parallel polarizations of the exciting and probing pulses are used. The sample concentration was adjusted to yield a transmission $T \approx 10 \%$ at $\lambda=865 \mathrm{~nm}$. At room temperature, non-adiabatic ET theory can be applied $[18,21]$ and the reaction is described by a rate equation system $[9,22]$. As a consequence we discuss the reaction model according to Fig. 1 where the intermediates $i$ and $j$ are connected by microscopic rates $\gamma_{i j}$. The principle of detailed balance is used to connect forward and backward rates: $\gamma_{j i}=\gamma_{i j} \exp \left[-\left(G_{i}-G_{j}\right) / k_{\mathrm{B}} T\right][19,23]$. The rates measured in the time-resolved experiments correspond to the eigenvalues of the rate matrix [9].

In the experiments, the RCs of Rhodobacter ( $R b$.) sphaeroides R26.1 are compared with modified RCs (R26.Phe-a) in which the bacteriopheophytin a (BPhe-a) molecules were exchanged to more than $95 \%$ by pheophytin a (Phe-a) by a procedure given in refs. $[24,25]$. The in vitro difference of the redox potential of BPhe-a and Phe-a of $\Delta U=0.13 \mathrm{~V}$ [26] suggests a comparable rise of $G\left(\mathrm{P}^{+} \mathrm{H}_{\mathrm{A}}^{-}\right)$in the modified RC. Since $G\left(\mathrm{P}^{+} \mathrm{H}_{\mathrm{A}}^{-}\right)$is about $0.2-0.25 \mathrm{eV}$ [27] below $G\left(\mathrm{P}^{*}\right)$ in the native $\mathrm{RC}$, the energy level of $\mathrm{P}^{+} \mathrm{H}_{\mathrm{A}}^{-}$in the modified $\mathrm{RC}$ should approach that of $P^{*}$. Thermal population of the states $P^{*}$ and possibly $\mathrm{P}^{+} \mathrm{B}_{\mathrm{A}}^{-}$(if its free energy is in the range of $G\left(\mathrm{P}^{*}\right)$ ) from the long-lived $\mathrm{P}^{+} \mathrm{H}_{\mathrm{A}}^{-}$can therefore be expected. Hence, time-resolved experiments on R26. Phe-a RCs should give information on the energetics of the different radical pairs allowing to decide between the two reaction models. 


\section{Results and discussion}

The analysis of extended time-resolved experiments (data not given here) within this model shows that $R 26 \cdot$ Phe-a is able to transfer the electron to $Q_{A}$ and that the same number of four intermediate states occurs in native RCs of R26.1 and in the modified R26.Phe-a. The main differences between the two kinds of RCs are:

(i) an unexpectedly weak bleaching in R26.Phe-a of the $\mathrm{Q}_{y}(\mathrm{H})$ band of Phe-a at $670 \mathrm{~nm}$, indicating a decreased population of $\mathrm{P}^{+} \mathrm{H}_{\mathrm{A}}^{-}$;

(ii) a reduced (due to increased recombination) concentration of $\mathrm{P}^{+} \mathrm{Q}_{\mathrm{A}}^{-}(70 \%)$ formed with a time constant of $370 \pm 100 \mathrm{ps}$; and

(iii) a long-lived population of $\mathrm{P}^{*}(3 \%)$ and $P^{+} B_{A^{-}}(30 \%)$ in $R 26 \cdot$ Phe-a, observed simultaneously with $\mathrm{P}^{+} \mathrm{H}_{\overline{\mathrm{A}}}^{-}$. This ratio of populations indicates that $G\left(\mathrm{P}^{*}\right)$ is well above $G\left(\mathrm{P}^{+} \mathrm{B}_{\mathrm{A}}^{-}\right)$, a finding which is in clear contrast to the superexchange model.

Direct evidence for the population of $\mathrm{P}^{+} \mathrm{B}_{\mathrm{A}}^{-}$is ob- tained from data at $1020 \mathrm{~nm}$ (Figs. $2 \mathrm{a}$ and $2 \mathrm{c}$ ), i.e. from a spectral region in which only the $\mathrm{BChl}$ anion has a pronounced absorption band $[26,28]$. Compared to R26.1 (Fig. 2a), the modified sample R26. Phe-a (Fig. 2c) behaves differently. In R26.1 $\mathrm{RCs}$, the absorption rises with $0.9 \mathrm{ps}$ and remains constant up to $1 \mathrm{~ns}$. This absorption at long delay times is only due to $\mathbf{P}^{+}[11]$. In R26. Phe-a, the absorption increases with 0.9 and 3.5 ps and shows a strong decay with $370 \mathrm{ps}$. Note, that in the unmodified RCs the absorption increase is less pronounced and that no slow decay is observed (Fig. 2a). Considering the spectral properties of the chromophores, the different behaviour of the two RCs can only be explained by a long-lived ( $370 \mathrm{ps)}$ population of approximately $30 \%$ of the $\mathrm{BChl}$ anion state $\mathrm{P}^{+} \mathrm{B}_{\mathrm{A}}^{-}$in R26.Phe-a.

A thermodynamic mixture of $\mathrm{P}^{+} \mathrm{B}_{\mathrm{A}}^{-}(80 \%)$ and $\mathrm{P}^{+} \mathrm{H}_{\mathrm{A}}^{-}(20 \%)$ was proposed [29] for the RCs of $\mathrm{R} 26 \cdot$ Phe-a from experiments performed in the more congested spectral region of the visible transitions of

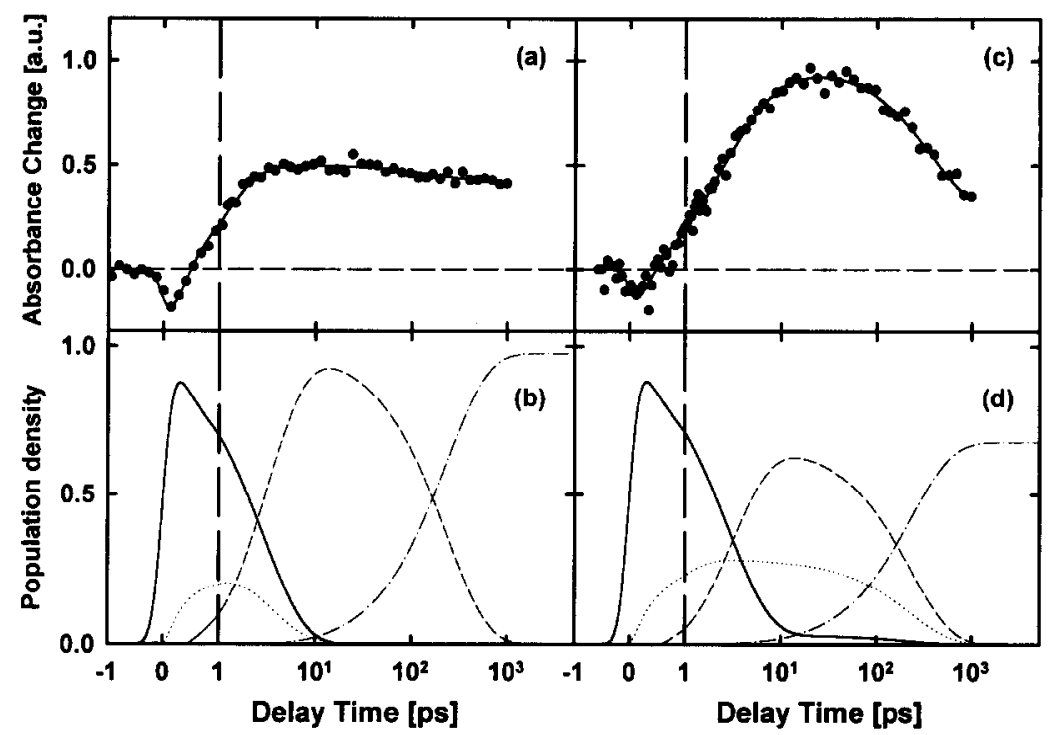

Fig. 2. Time-resolved absorption differences $\Delta A\left(t_{\mathbf{D}}\right)$ on unmodified RCs from $R b$. sphaeroides $\mathrm{R} 26.1(\odot)$. The solid line represents a model function calculated according to the simulation of the ET reaction in the scope of the step-wise reaction model of Fig. 1 with the data from Table 1 . Note the linear scale for the delay times of $<1 \mathrm{ps}$ and the logarithmic scale at later delay times. (b) Transient

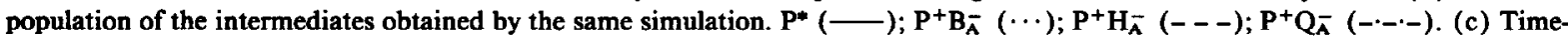
resolved absorption data $\Delta A\left(t_{\mathrm{D}}\right)$ for the modified reaction centers $\mathrm{R} 26 \cdot \mathrm{Phe}-\mathrm{a}(O)$. The data show a long-living population of the radical pair $\mathrm{P}^{+} \mathrm{B}_{\mathrm{A}}^{-}$related to increased absorption between $t_{\mathrm{D}} \approx 3 \mathrm{ps}$ and $t_{\mathrm{D}} \approx 400 \mathrm{ps}$. The rise in the energy of intermediate $\mathrm{P}^{+} \mathrm{H}_{\bar{A}}^{-}$due to chromophore exchange apparently causes this long-lived population of the bacteriochlorophyll anion. (d) Transient population of the intermediates for R26.Phe-a, line markings as in (b). 
Table 1

Microscopic rates and free energies deduced within the step-wise reaction model of Fig. 1 for R26.1 RCs and modified pheophytin a containing RCs, R26.Phe-a

\begin{tabular}{lcllllll}
\hline Type & $1 / \gamma_{12}$ & $1 / \gamma_{23}$ & $1 / \gamma_{34}$ & $1 / \gamma_{10}$ & $1 / \gamma_{20}$ & $\Delta G\left(\mathrm{P}^{+} \mathrm{B}_{\mathrm{A}}^{-}\right)$ & $\Delta G\left(\mathrm{P}^{+} \mathrm{H}_{\mathrm{A}}^{-}\right)$ \\
\hline R26.1 & $2.3 \mathrm{ps}$ & $0.9 \mathrm{ps}$ & $200 \mathrm{ps}$ & $190 \mathrm{ps}^{\mathrm{b}}$ & $500-1000 \mathrm{ps}$ & $-450 \mathrm{~cm}^{-1 \mathrm{~d}}$ & $-2000 \mathrm{~cm}^{-1 \mathrm{e}}$ \\
R26.Phe-a & $\begin{array}{r}(7 \mathrm{ps})^{\mathrm{a}} \\
3.5 \mathrm{ps}\end{array}$ & $1.5 \mathrm{ps}$ & $350 \mathrm{ps}$ & $190 \mathrm{ps}^{\mathrm{b}}$ & $500-1000 \mathrm{ps}$ & $-450 \mathrm{~cm}^{-1}$ & $-630 \mathrm{~cm}^{-1}$ \\
& $(20 \mathrm{ps})^{\mathrm{a}}$ & & & & & & \\
\hline
\end{tabular}

Second time constant for the biexponential fit of the decay of $\mathrm{P}^{*}$ not considered in the present analysis.

b Fixed value from ref. [30]. ' $N o t$ required for data analysis.

d Taken from analysis of R26.Phe-a. ' Fixed value from ref. [27].

Phe-a. In contrast, the much lower population of $\mathbf{P}^{+} \mathbf{B}_{\mathbf{A}}^{-}$reported in this Letter is directly deduced from data taken in the clean spectral region around 1020 nm (Figs. 2a and 2c).

Within the reaction model of Fig. 1, the microscopic rates and free energy levels (given in Table 1) can be estimated from the experimental results. In the analysis for $\mathrm{R} 26 \cdot \mathrm{Phe}-\mathrm{a}, 1 / \gamma_{20}, \Delta G\left(\mathrm{P}+\mathrm{B}_{\mathrm{A}}\right)$ and $\Delta G\left(\mathrm{P}^{+} \mathrm{H}_{\mathrm{A}}^{-}\right)$were varied as free parameters to reproduce the measured time constants and absorbance changes of the intermediates. We considered recombination from $\mathrm{P}^{*}$ and $\mathrm{P}^{+} \mathrm{B}_{\mathrm{A}}^{-}$to the ground state $\mathrm{P}$ in order to explain the reduced efficiency in $Q_{\bar{A}}^{-}$formation. Consistency is only obtained if the free energy of the intermediate $\mathrm{P}^{+} \mathrm{B}_{\mathrm{A}}^{-}$is approximately 450 $\mathrm{cm}^{-1}$ below $\mathrm{P}^{*}$ and $180 \mathrm{~cm}^{-1}$ above $\mathrm{P}^{+} \mathrm{H}_{\mathrm{A}}^{-}$. The value $\quad \Delta G\left(\mathrm{P}^{+} \mathrm{H}_{\overline{\mathrm{A}}}^{-}\right)=G\left(\mathrm{P}^{+} \mathrm{H}_{\mathrm{A}}^{-}\right)-G\left(\mathrm{P}^{*}\right)=-630$ $\mathrm{cm}^{-1}$ is in the range one expects from the change in redox potential. The microscopic rates for the process $B_{\mathbf{A}}^{-} \rightarrow H_{\mathbf{A}}^{-}(1.5$ ps instead of 0.9 ps $)$ and $\mathrm{H}_{\mathbf{A}}^{-} \rightarrow$ $\mathrm{Q}_{\mathrm{A}}^{-}(350 \mathrm{ps}$ instead of $200 \mathrm{ps})$ are well understood in view of the exchange of the BPhe-a and the related alterations in free energy. The increase in the decay time $\left(1 / \gamma_{12}\right)$ of $\mathrm{P}^{*}$ apparently is due to weak modification of the energy of $\mathrm{P}^{+} \mathrm{B}_{\overline{\mathrm{A}}}^{-}$induced e.g. by the smaller polarity of pheophytin a compared to bacteriopheophytin a (replacement of the 3-acetyl by a vinyl group). Nevertheless, the value $\Delta G\left(\mathrm{P}^{+} \mathrm{B}_{\mathrm{A}}^{-}\right) \approx$ $-450 \mathrm{~cm}^{-1}$ can be used as a first estimate for native RCs since the modification is not expected to lead to pronounced changes in $\Delta G\left(\mathrm{P}^{+} \mathrm{B}_{\mathrm{A}}^{-}\right)$. The population densities of the intermediate states for the two types of RCs according to the reaction model of Fig. 1 are shown in Figs. 2b and 2d. They allow a good model- ing of the transient absorption dynamics of the two samples.

The replacement of bacteriopheophytin a by pheophytin a leads to significant modifications of the absorption kinetics and, in particular, to a relatively long-lived population of the radical pair state $\mathrm{P}^{+} \mathbf{B}_{\mathbf{A}}^{-}$. The free energy levels for the intermediates $\mathrm{P}^{+} \mathrm{B}_{\mathrm{A}}^{-}$and $\mathrm{P}^{+} \mathrm{H}_{\mathrm{A}}^{-}$deduced from these data strongly support the step-wise ET model. The details of the reaction scheme, the order of the time constants and the energies of the intermediates can be understood from the optimization of the primary ET in wild-type RC [31]. The forward ET to the bacteriopheophytins is accelerated by a primary reaction involving two subsequent steps between neighbouring chromophores. Back reaction and recombinations are slowed down since large energy gaps exist between $\mathrm{P}^{+} \mathbf{B}_{\mathbf{A}}^{-}$, $\mathrm{P}^{+} \mathrm{H}_{\mathrm{A}}^{-}$and $\mathrm{P}^{*}$. Both effects lead to an optimum use of the light energy in primary photosynthesis.

\section{References}

[1] J. Deisenhofer and H. Michel, EMBO J. 8 (1989) 2149.

[2] J.P. Allen, G. Feher, T.O. Yeates, H. Komiya and D.C. Rees, Proc. Natl. Acad. Sci. US 84 (1987) 5730.

[3] M. Schiffer and J.M. Norris, in: The photosynthetic reaction center, Vol. I, eds. J. Deisenhofer and J.R. Norris (Academic Press, San Diego, 1993) p. 1.

[4] J.R. Norris, H. Scheer, M.E. Druyan and J.J. Katz, Proc. Natl. Acad. Sci. US 71 (1974) 4897.

[5] J.L. Martin, J. Breton, A.J. Hoff, A. Migus and A. Antonetti, Proc. Natl. Acad. Sci. US 83 (1986) 957.

[6] C. Kirmaier and D. Holten, Proc. Natl. Acad. Sci. US 87 (1990) 3552.

[7] C.-K. Chan, T.J. DiMagno, L.X.-Q. Chen, J.R. Norris and G.R. Fleming, Proc. Natl. Acad. Sci. US 88 (1991) 11202. 
[8] W. Holzapfel, U. Finkele, W. Kaiser, D. Oesterhelt, H. Scheer, H.U. Stilz and W. Zinth, Chem. Phys. Letters 160 (1989) 1.

[9] W. Holzapfel, U. Finkele, W. Kaiser, D. Oesterhelt, H. Scheer, H.U. Stilz and W. Zinth, Proc. Natl. Acad. Sci. US 87 (1990) 5168.

[10] K. Dressler, E. Umlauf, S. Schmidt, P. Hamm, W. Zinth, S. Buchanan and H. Michel, Chem. Phys. Letters 183 (1991) 270.

[11] T. Arlt, S. Schmidt, W. Kaiser, C. Lauterwasser, M. Meyer, H. Scheer and W. Zinth, Proc. Natl. Acad. Sci. US 90 (1993) 11757.

[12] M. Du, S.J. Rosenthal, X. Xie, T.J. DiMagno, M. Schmidt, D.K. Hanson, M. Schiffer, J.R. Norris and G.R. Fleming, Proc. Natl. Acad. Sci. US 89 (1992) 8517.

[13] P. Hamm, K.A. Gray, D. Oesterhelt, R. Feick, H. Scheer and W. Zinth, Biochim. Biophys. Acta 1142 (1993) 99.

[14] W.W. Parson, Ann. Rev. Biophys. Bioeng. 11 (1982) 57.

[15] N.W. Woodbury, M. Becker, D. Middendorf and W.W. Parson, Biochemistry 24 (1985) 7516.

[16] R.A. Marcus, Chem. Phys. Letters 133 (1987) 471.

[17] R.A. Marcus, in: The photosynthetic bacterial reaction center: structure and dynamics, eds. J. Breton and A. Vermeglio (Plenum Press, New York, 1988) p. 389.

[18] M. Bixon, M.E. Michel-Beyerle and J. Jortner, Israel J. Chem. 28 (1988) 155.

[19] M. Bixon, J. Jortner and M.E. Michel-Beyerle, Biochim. Biophys. Acta 1056 (1991) 301.
[20] S. Schmidt, T. Arlt, P. Hamm, C. Lauterwasser, U. Finkele, G. Drews and W. Zinth, Biochim. Biophys. Acta 1144 (1993) 385.

[21] M.H. Vos, F. Rappaport, J.-C. Lambry, J. Breton and J.L. Martin, Nature 363 (1993) 320.

[22] U. Finkele, K. Dressler, C. Lauterwasser and W. Zinth, in: Reaction centers of photosynthetic bacteria, ed. M.-E. Michel-Beyerle (Springer, Berlin, 1990) p. 127.

[23] M. Bixon, J. Jortner, M.E. Michel-Beyerle, A. Ogrodnik and W. Lersch, Chem. Phys. Letters 140 (1987) 626.

[24] H. Scheer, M. Meyer and I. Katheder, in: The photosynthetic bacterial reaction centers: structure, spectroscopy and dynamics, eds. J. Breton and A. Vermeglio (Plenum Press, New York, 1992) p. 49.

[25] H. Scheer and A. Struck, in: The photosynthetic reaction center, Vol. I, eds. J. Deisenhofer and J.R. Norris (Academic Press, New York, 1993) p. 157.

[26] I. Fujita, M.S. Davis and J. Fajer, J. Am. Chem. Soc. 100 (1978) 6280.

[27] A. Ogrodnik, Biochim. Biophys. Acta 1020 (1990) 65 .

[28] J. Fajer, D.C. Brune, M.S. Davis, A. Forman and L.D. Spaulding, Proc. Natl. Acad. Sci. US 72 (1975) 4956.

[29] A.Y. Shkuropatov and V.A. Shuvalov, FEBS Letters 322 (1993) 168.

[30] J. Breton, J.-L. Martin, S.J. Robles and D.C. Youvan, in: Reaction centers of photosynthetic bacteria, ed. M.E. Michel-Beyerle (Springer, Berlin, 1990) p. 293.

[31 ] H. Kuhn, Phys. Rev. A 34 (1986) 3409. 